\title{
CARACTERIZAÇÃO DO RESÍDUO DE ACEROLA VISANDO A CONVERSÃO TERMOQUÍMICA
}

\author{
G. A. N. BARBOSA ${ }^{1}$, G. S. SEHNEM ${ }^{1}$, G. D. R. NOGUEIRA ${ }^{1}$, C. R. DUARTE ${ }^{1}$ e M. A. S. \\ BARROZO $^{1}$
}

${ }^{1}$ Universidade Federal de Uberlândia, Faculdade de Engenharia Química

E-mail para contato: g.n.barbosa@hotmail.com; gabisella@ hotmail.com

\begin{abstract}
RESUMO - A biomassa apresenta uma grande vantagem na perspectiva ambiental, por auxiliar na redução dos impactos ambientais e dos poluentes presentes na atmosfera. O Brasil é considerado um dos maiores produtores agrícolas mundiais, e com isso gera-se uma grande quantidade de resíduos, que podem ser reutilizados, como biomassa, para a produção de energia, combustíveis líquidos, sólidos e gasosos, dentre outros materiais. A acerola é um produto presente na produção agrícola nacional, por ser bem adaptado ao clima brasileiro e apresentar alto valor nutritivo e energético para a alimentação. A caracterização do resíduo da acerola foi obtida pelos procedimentos de análise imediata, regidos pelas normas da ASTM, de análise somativa, regidos pela Embrapa, e de análise elementar. Os teores de cinzas encontrados foram de 3,25\%, umidade de $80,84 \%$, carbono fixo de $21,42 \%$ e voláteis de $75,33 \%$. Já o teor de carbono encontrado foi de $47,48 \%$ juntamente com um teor de lignina insolúvel de $29,85 \%$. Com os testes realizados considerou-se o resíduo de acerola uma potencial biomassa a ser utilizado em processos de conversão térmica, como a carbonização hidrotérmica (HTC).
\end{abstract}

\section{INTRODUÇÃO}

O Brasil é um dos maiores produtores agrícola do mundo, e devida à alta produtividade gera-se uma grande quantidade de resíduos. Diversas pesquisas buscam soluções para a reutilização desses resíduos, como biomassa percussora para a obtenção de energia renovável (Brasil, 2009).

Durante o processamento de frutas para a produção de sucos, geleias e polpas congeladas, diversas partes são desprezadas, dentre elas as cascas, sementes e o bagaço, originando um volume grande de resíduos. Além de gerar problemas ambientais, os resíduos constituem perda de matérias-primas e energia, requerem investimentos expressivos em tratamentos para controlar a poluição. Dependendo da fruta, a produção de resíduos pode chegar a até $50 \%$ da matéria-prima, e se for empregada uma tecnologia adequada, este material pode ser convertido em produtos comerciais ou matérias-primas para processos secundários. (Nunes et al, 2015).

A biomassa apresenta a vantagem de gerar um baixo impacto ambiental e reduzir de forma significativa às emissões de gases tóxicos na atmosfera. A partir da biomassa diversos produtos podem ser gerados, tais como, energia, combustíveis líquidos, sólidos e gasosos, 
químicos, energia elétrica e materiais avançados. Como fonte de energia renovável, na literatura já se encontra diversos processos e estudos sobre técnicas de utilizar os resíduos gerados pelas grandes indústrias. (Oliveira et al, 2014).

A solução para reduzir esse volume foi agregar valor aos subprodutos e apresentar um destino para esse material. Pois apesar de este ser biodegradável ele necessita de um tempo de decomposição, transformando-se, assim, em um possível poluente ambiental. Esses subprodutos podem apresentar um grande fator energético e nutritivo. Destacando-se a acerola, uma fruta de fácil cultivo e grande fonte de nutrientes e vitaminas, com produção média de 59,3 kg/planta ano. (Marques, 2013).

Assim, o objetivo do trabalho foi caracterizar o resíduo de acerola através de análise imediata, tais como teores de umidade, cinzas, voláteis e carbono fixo, análise elementar e somativa, para obter as características dessa biomassa com o intuito de geração de energia, através de processos, como a carbonização hidrotérmica (HTC).

\section{MATERIAL E MÉTODO}

As amostras de resíduos agroindustriais de acerola, ilustrada na Figura 1, foram adquiridas junto à indústria de processamento Fruteza, localizada no município de Dracena SP. As quais foram separadas em porções pequenas, etiquetadas e congeladas em freezer doméstico no Laboratório de Sistemas Particulados (LSP) da Faculdade de Engenharia Química da Universidade Federal de Uberlândia.

\section{Figura 1 - Resíduo de acerola.}

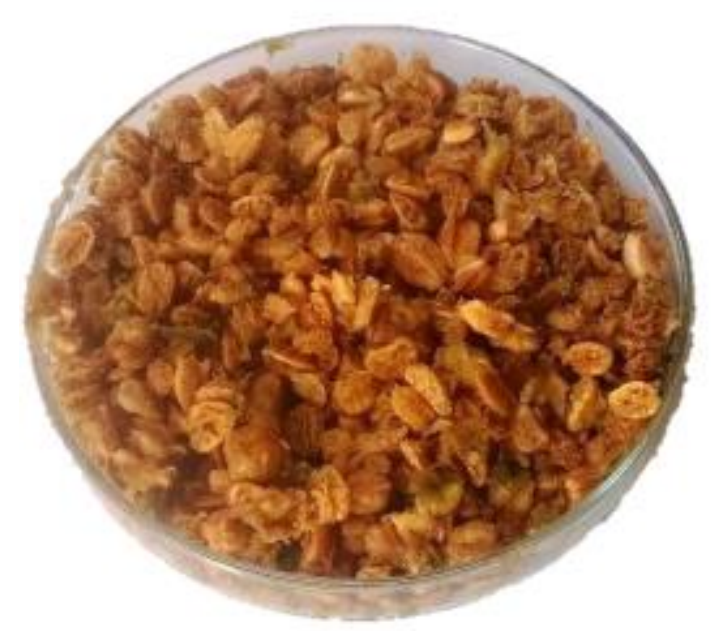

Antes da realização das análises, as amostras congeladas foram retiradas do freezer e colocadas em geladeira até o seu descongelamento pelo período de $24 \mathrm{~h}$. Após o descongelamento, as amostras foram secas em estufa com temperatura de $105^{\circ} \mathrm{C}$.

A primeira etapa de caracterização do resíduo da acerola foi a análise imediata, na qual consistia a determinação dos teores de umidade, materiais voláteis, cinzas e carbono fixo. 
Para a determinação do teor de voláteis utilizou-se como base o método ASTM E872-82, em que as amostras eram submetidas à temperaturas em torno de $950{ }^{\circ} \mathrm{C}$ por um intervalo de tempo de 7 min.

A determinação do teor de cinzas consistia num procedimento em que a amostra era aquecida em mufla em uma temperatura média de $700{ }^{\circ} \mathrm{C}$ por um intervalo de $4 \mathrm{~h}$ obedecendo aos métodos da ASTM E1534-93. Já a determinação de umidade foi realizada através do método de secagem em mufla de acordo com a norma ASTM E871-82. E, para a determinação do teor de carbono fixo, utilizou-se a diferença conforme a norma ASTM Standard D3172.

A segunda etapa de caracterização do resíduo da acerola foi a análise elementar, que consiste na determinação dos teores dos compostos elementares, tais quais: carbono, hidrogênio, nitrogênio e enxofre. O equipamento utilizado foi o CHNS/O 2400 da Perkin Elmer, e o teor de oxigênio encontrado na amostra foi determinado pela Equação 1:

$$
\% \mathrm{O}=100-(\% \mathrm{C}+\% \mathrm{H}+\% \mathrm{~N}+\% \mathrm{~S})
$$

Por fim, foram realizadas as análises somativa, nas quais as quantificações dos extrativos e ligninas foram realizadas segundo as normas T204 cm-97 e T222 om-02 da Technical Association of the Pulp and Peper Industry (TAPPI), respectivamente. Já as determinações dos percentuais de celulose e hemicelulose seguiram os procedimentos sugeridos pela Empraba (Moraes et al, 2002).

\section{RESULTADOS E DISCUSSÕES}

O estudo e a caracterização do resíduo de acerola foram realizados com foco principal para a posterior conversão térmica visando combustíveis sólidos e líquidos através da carbonização hidrotérmica (hidrochar).

O resíduo de acerola apresentou um alto teor de umidade, o qual foi de $80,84 \pm 1,31 \%$ em base úmida, sendo que em comparação com Silva (2015), o encontrado foi de $79,38 \% \pm 1,46$. Assim, nesses processos em que a secagem prévia do material torna-se desnecessária (carbonização hidrotérmica) pode-se representar um importante ganho econômico. Na Tabela 1, encontram-se os dados obtidos pela análise imediata do resíduo de acerola:

Tabela 1 - Análise imediata do resíduo de acerola.

\begin{tabular}{|c|c|}
\hline Componentes & Valor (\%) \pm Desvio Padrão \\
\hline Umidade & $80,84 \pm 1,31$ \\
\hline Cinzas & $3,25 \pm 0,15$ \\
\hline Teor de matéria volátil & $75,33 \pm 0,72$ \\
\hline Teor de carbono Fixo (Base seca) & $21,42 \pm 0,65$ \\
\hline
\end{tabular}


O teor de cinzas para o resíduo de acerola encontrado foi de $3,25 \pm 0,15 \%$, e o descrito por Silva (2014) foi de 3,04\%. Este valor se aproxima ao de precursores tradicionais para a produção de carvão como as madeiras de Angico-Vermelho, Jurema-Preta e JuremaVermelha (Santos et al., 2012).

O baixo teor de cinzas é uma das características que devem ser consideradas na escolha do material precursor para a produção de carvão, pois as cinzas são constituintes inorgânicos que não participam da produção de energia e são resíduos após a reação de combustão (Couto et al, 2009). As cinzas em doses elevadas podem prejudicar e até mesmo limitar a aplicação industrial do carvão gerado (Macêdo, 2012).

Já na Tabela 2, encontram-se os valores obtidos pela análise elementar, sendo os teores de oxigênio, carbono, hidrogênio, enxofre e nitrogênio. Essa análise se faz necessária principalmente para determinação da fonte de carbono presente na amostra de biomassa.

Tabela 2 - Análise elementar do resíduo de acerola.

\begin{tabular}{|c|c|}
\hline Elemento & Valor (\%) \pm Desvio Padrão \\
\hline Carbono $(\mathrm{C})$ & $47,48 \pm 0,18$ \\
\hline Hidrogênio $(\mathrm{H})$ & $6,00 \pm 0,10$ \\
\hline Nitrogênio $(\mathrm{N})$ & $1,66 \pm 0,27$ \\
\hline Enxofre (S) & $0,03 \pm 0,02$ \\
\hline Oxigênio $(\mathrm{O})$ & $44,87 \pm 0,29$ \\
\hline
\end{tabular}

Observaram-se altos valores de carbono na composição elementar do resíduo de acerola. Soares (2011) verificou teores de carbono na composição da madeira híbrida de Eucalyptus urophylla x Eucalyptus grandis para composição de carvão proveniente de madeiras de eucaliptos, entre $43,97 \%$ e $45,60 \%$ dependo da idade de corte. Tal madeira rendeu carvões com teor de carbono entre $81,28 \%$ e $79,81 \%$.

Segundo Couto et al (2009), matérias-primas com o teor de carbono acoplado ao baixo teor de cinzas constituem bons precursores para a produção de carvão, ilustrando uma boa perspectiva para os resultados posteriores para o resíduo de acerola.

$\mathrm{Na}$ Tabela 3 são apresentados os resultados para a análise dos subcomponentes do resíduo de acerola provenientes da análise somativa para componentes como extrativos, ligninas e celuloses:

Tabela 3 - Análise de subcomponentes para o resíduo de acerola.

\begin{tabular}{|c|c|}
\hline Elemento & Valor (\%) \pm Desvio Padrão \\
\hline Extrativos & $6,01 \pm 1,78$ \\
\hline Lignina insolúvel & $29,85 \pm 1,82$ \\
\hline
\end{tabular}




\begin{tabular}{|c|c|}
\hline Lignina Solúvel & $1,58 \pm 0,13$ \\
\hline Holocelulose & $54,92 \pm 0,52$ \\
\hline Hemicelulose & $29,85 \pm 1,82$ \\
\hline Alfacelulose & $27,23 \pm 7,64$ \\
\hline
\end{tabular}

A combinação de hemicelulose com alfacelulose é chamada de holocelulose. A hemicelulose se diferencia da alfacelulose pelo fato de que as hemiceluloses possuem unidades de açúcares diferentes de cinco ou seis átomos de carbono (Santos et al, 2012) e a alfa-celulose é a holocelulose não degradada. A diferença básica entre a celulose degradada e a não degradada é o tamanho da molécula e o número de resíduos de glicose presentes (Pereira, 2010).

A composição biomássica do material precursor para a produção de carvão está diretamente ligada à estrutura microporosa do produto final, portanto é de extrema utilidade a análise desta composição. A lignina é a principal fonte de carbono puro da matéria, enquanto a celulose compõe as frações voláteis da biomassa. Reed e Williams (2004) estudando diversas biomassas com teores de subcomponentes significativamente diferentes obtiveram maiores rendimentos de carvão para biomassas com teores de lignina mais altos.

\section{CONCLUSÃO}

Os testes determinaram um alto teor de carbono presente na análise elementar do resíduo de acerola, comparando-o com fontes tradicionais da carbonização. Assim, o resíduo da acerola renderia um carvão com alto teor de carbono e consequentemente alto poder calorífico superior. Associando-se aos altos teores de lignina, o que poderá apresentar maiores rendimentos em carvão.

Assim, todos os resultados realizados neste trabalho validam a possibilidade da utilização do resíduo da acerola como percursor de geração de energia, sendo a carbonização hidrotérmica (HTC), um exemplo de processo a ser aplicado.

\section{REFERÊNCIAS.}

BRASIL, Agência Nacional de Energia Elétrica (Aneel). Atlas de Energia Elétrica do Brasil, 2009. Disponível em: www. aneel.gov.br. Acesso em 14/03/2017 às 14h15.

COUTO R. O; VALGAS A. B; BARA M. T. F; PAULA J. R. Caracterização físico-química do pó das folhas de Eugenia dysenterica dc. (Myrtaceae). Rev Eletr Farm. 2009.

MACÊDO, L. P. M. P. Viabilidade da produção de carvão ativado a partir de resíduos alternativos. Dissertação (Mestrado) - Universidade Católica De Pernambuco, 2012.

MARQUES, T. R. Aproveitamento tecnológico de resíduos de acerola: farinhas e barras de cereais, 2013. Dissertação (Mestrado em Agroquímica) - Universidade Federal de Lavras, Lavras, 2013. 
MORAES, J. A. P. V; NOGUEIRA, R. J. M. C; BURITY, H. A. et al. Efeito do estádio de maturação dos frutos nas características físico-químicas de acerola. Pesquisa Agropecuária Brasileira, Brasília, v.37, n.4, p.463-470, 2002.

NUNES, J. S; DA SILVA, F. B; GOMES, J. P; DA SILVA, W. P. Caracterização físicoQuímica da farinha resíduo de polpa de acerola. Congresso Técnico Científico de Engenharia e da Agronomia - CONTECC, 2015. Universidade Federal de Campina Grande.

OLIVEIRA, I. B; SANTOS, M. C. G; BARIN, G. B; BARRETO, L. S. Influência da carbonização hidrotérmica e do tratamento por microondas na morfologia de materiais carbonáceos obtidos de lignina. Tese - Universidade Federal de Sergipe, Sergipe, 2014.

PEREIRA, A. L. S. Extração de nanocelulose de fibras vegetais. Trabalho de conclusão de curso em Graduação em Engenharia Química - Universidade Federal do Ceará, Fortaleza, 2010.

REED, A. R.; WILLIAMS, P. T. Thermal processing of biomass natural fiber wastes by pyrolysis, International Journal of Energy Research, v. 28, p. 131-145, 2004.

SANTOS, H. C. M; PAES, J. B; LIMA, C. R; OLIVEIRA, E. Ciência da Madeira (Braz. J. Wood Sci.), Pelotas, v. 03, n. 01, p. 01-10, Maio de 2012.

SILVA, P. B. Secagem de Resíduos de Frutas em Secador Roto-Aerado. Dissertação (Mestrado no Programa de Pós-Graduação em Engenharia Química) - Universidade Federal de Uberlândia, Uberlândia, 2014.

SILVA, D. I. S. Estudo da transferência de calor e massa na secagem em leito fixo visando o aproveitamento de resíduo de acerola (Malpighia Emarginata dc). Tese (Doutorado no Programa de Pós-Graduação em Engenharia Química) - Universidade Federal de Uberlândia, Uberlândia, 2015.

SOARES V. C. Comportamento térmico, químico e físico da madeira e do carvão de Eucalyptus urophylla X Eucalyptus grandis em diferentes idades. Tese (Doutorado no Programa de Pós-Graduação em Ciência e Tecnologia da Madeira) - Universidade Federal de Lavras, Lavras, 2011. 